OPEN ACCESS

Edited by:

Salvatore Salomone,

University of Catania, Italy

Reviewed by:

Jose Antonio Ortega Martinez, Italian Institute of Technology (IIT), Italy

Pierfausto Seneci,

University of Milan, Italy

*Correspondence:

Chong Wang

fccwangc@zzu.edu.cn

Specialty section:

This article was submitted to Experimental Pharmacology

and Drug Discovery,

a section of the journal

Frontiers in Pharmacology

Received: 04 February 2021 Accepted: 09 March 2021

Published: 29 April 2021

Citation:

Wang A, Li L, Li M, Wang S and Wang $C$ (2021) 7-Ethyl-10-

Hydroxycamptothecin, a DNA

Topoisomerase I Inhibitor, Performs BRD4 Inhibitory Activity and Inhibits

Human Leukemic Cell Growth.

Front. Pharmacol. 12:664176.

doi: 10.3389/fphar.2021.664176

\section{7-Ethyl-10-Hydroxycamptothecin, a DNA Topoisomerase I Inhibitor, Performs BRD4 Inhibitory Activity and Inhibits Human Leukemic Cell Growth}

\author{
Airong Wang, Lingling Li, Mengya Li, Shujuan Wang and Chong Wang *
}

Department of Hematology, The First Affiliated Hospital of Zhengzhou University, Zhengzhou, China

7-Ethyl-10-hydroxycamptothecin (SN-38) is an active metabolite of CPT-11, which can inhibit DNA topoisomerase I, DNA synthesis and cause frequent DNA single-strand breaks. In our study, SN-38 was characterized as a potent and reversible BRD4 inhibitor $\left[\mathrm{IC}_{50}=660.2 \mathrm{nM}\right.$ against $\mathrm{BRD} 4(\mathrm{BD} 1)$ and $\mathrm{IC}_{50}=547.7 \mathrm{nM}$ against BRD4 (BD2)] in biochemical assay using drug repurposing strategy. Additional cellular assay suggested that SN-38 can bind BRD4 in human leukemic cell K562 and inhibit cell growth with $\mathrm{IC}_{50}=0.2798 \mu \mathrm{M}$ in a BRD4 dependent manner partially. Additionally, mechanism study indicated that SN-38 can induce the accumulation of BRD4 substrate c-Myc and cleavage of caspase 3. In sum, our findings identified BRD4 as a new target of SN-38 and reveals SN-38 as a modifier of histone acetylation reader for the first time, which may provide a new insight for further optimization of dual target inhibitor.

Keywords: SN-38, BRD4, inhibitor, leukemic cell, growth

\section{INTRODUCTION}

Epigenetics is the study of heritable phenotype changes that do not involve alterations in the DNA sequence. While genetic changes can alter which protein is produced, epigenetic changes affect gene expression to turn genes "on" and "off." Among the diverse kinds of epigenetics, histone modification is the key player in regulating gene expression, including methylation, phosphorylation, acetylation, ubiquitylation, and sumoylation (Feinberg and Tycko, 2004). These covalent post-translational modification (PTM) on histone proteins can impact gene expression by altering chromatin structure or recruiting histone modifiers.

There are three groups of epigenetic modifiers, and referred to as "writers," "erasers," and "readers" (Marmorstein and Roth, 2001). As a family of key proteins in epigenetics, bromodomain (BRD)-containing proteins family can specifically recognize and bind acetylated lysine on histones as a readers of lysine acetylation (Filippakopoulos and Knapp, 2014). The BRD family is highly conserved during evolution, and the bromodomain and terminal outer domain (BET) protein family belongs to the BRD protein family. It is composed of bromodomain-containing protein 2 (BRD2), bromodomain-containing protein 3 (BRD3), bromodomain-containing protein 4 (BRD4) and bromodomain testis-specific protein (BRDT) consists of four members, each of which contains two tandem BRDs (BD1 and BD2) and an extra terminal domain (ET) (Wu and Chiang, 2007; Filippakopoulos et al., 2012; Taniguchi, 2016). BRD4 is currently the most widely studied member of 
the BRD family. It can recognize and bind histone and nonhistone acetylated lysine to participate in the development of many diseases (Moriniere et al., 2009). Recent reports indicating that BRD4 is highly expressed in various cancers, including gastric cancer, breast cancer, leukemia and so on (Sahai et al., 2016; Kulikowski et al., 2021), and is involved in regulating cell growth, cell cycle and apoptosis, and other cell processes. Its imbalance is related to the occurrence and development of many cancers. In addition, BRD4 can recruit and activate $\mathrm{p}-\mathrm{TEFb}$ (transcription elongation factor $\mathrm{b}$ ), and activated $\mathrm{p}-\mathrm{TEFb}$ can phosphorylate RNA Pol II (Itzen et al., 2014; Fujinaga et al., 2015), thereby promoting oncogenes (c-MYC) transcription extension (Roe et al., 2015).

Until now, a large number of studies have shown that BRD4 inhibitor has shown good antitumor activity in a variety of malignancies, and a variety of BRD4 inhibitor has been used in clinical trials of hematological malignancies, solid tumors, inflammation and cardiovascular diseases (Schaefer, 2014), and several inhibitors have entered the clinical phase (Theodoulou et al., 2016; Alqahtani et al., 2019), including OTX015 (NCT02259114), GSK525762 (NCT01587703), TEN-010 (NCT02308761) and CPI-0610 (NCT01949883 and NCT02157636), they were used to treat lymphoma, acute myeloid leukemia, multiple myeloma and myelodysplastic syndrome, etc. Unfortunately, none of them have entered clinical stages in recent years (Andrieu et al., 2016). So, new potent BRD4 inhibitor with novel skeleton is still in needed.

In this present study, SN-38 was identified by high throughput screening with BRD4 inhibitor screening assay from a small compound library. Then, SN-38 was characterized to inhibit BRD4(BD1) and BRD4(BD2) potently and reversibly. Additional cellular study suggested that SN-38 can suppress the proliferation of chronic myelogenous leukaemia (CML) cell line K562. In a nutshell, this finding gave a support that SN-38 may serve as a lead compound to inhibit CML proliferation by targeting BRD4.

\section{MATERIALS AND METHODS}

\section{Cell Culture and Materials}

K562 cell line was obtained from National Collection of Authenticated Cell Cultures (Shanghai, China) and cultured in Roswell Park Memorial Institute (RPMI) 1640 medium (Solarbio, China) supplemented with $10 \%$ fetal bovine serum (FBS) (Biological Industries, Israel) and $1 \%$ penicillin-streptomycin. Cells were maintained at $37^{\circ} \mathrm{C}$ in a humidified atmosphere of 95\% air and $5 \% \mathrm{CO}_{2}$.

Raloxifene was purchased from commercial source (MB1615, meilunbio, China) and the purity is above $98 \%$ and prepared at concentration of $10 \mathrm{mM}$ with dimethyl sulfoxide (DMSO) for stock. The highest DMSO concentration in the medium was $<0.1 \% \mathrm{v} / \mathrm{v}$, which had no any substantial effect on the cell.

\section{Cell Viability Assay}

CCK-8 (Beyotime Biotechnology, China) was used to determine cell viability. Cells were seeded in 96-well plates at a density of
2,000 per well, and treated with series of compounds. After 48, 72 or $96 \mathrm{~h}$ incubation, $10 \mu \mathrm{lCCK}-8$ solution was added to each well and incubated for additional $3 \mathrm{~h}$ at $37^{\circ} \mathrm{C}$. Then the plate was read by multiplate reader (PE Envision, United States) at $570 \mathrm{~nm} . \mathrm{IC}_{50}$ was calculated by the GraphPad Prism 9.0 software.

\section{Expression and Purification of BRD4(BD1) and BRD4(BD2)}

Genes encoding BRD4(BD1) and BRD4(BD2) were cloned into pGEX-4T-1 plasmid by double digestion, respectively. Then, the reconstructed plasmid was transfected into E. coli BL21(DE3) cells, and grown overnight at $37^{\circ} \mathrm{C}$ in $50 \mathrm{ml}$ of Terrific Broth (TB) medium. Then the medium was diluted 100 -fold in $1 \mathrm{~L}$ of fresh $\mathrm{TB}$ medium and cell growth was at $37^{\circ} \mathrm{C}$ to an optical density of about 0.8 at OD600 before the temperature was decreased to $15^{\circ} \mathrm{C}$. Then, cells were grown overnight at $15^{\circ} \mathrm{C}$ in the presence of $0.5 \mathrm{mM}$ isopropyl- $\beta$-D-thiogalactopyranoside (IPTG). Cells were collected by centrifugation $\left(5,000 \mathrm{~g}\right.$ for $15 \mathrm{~min}$ at $\left.4^{\circ} \mathrm{C}\right)$ and resuspended in lysis buffer $[50 \mathrm{mM}$ tris (hydroxymethyl) aminomethane (Tris), $\mathrm{pH} 7.3,300 \mathrm{mM} \mathrm{NaCl}, 10 \mathrm{mM}$ imidazole, 5\% glycerol with freshly added $0.5 \mathrm{mM}$ tris (2carboxyethyl) phosphine hydrochloride (TCEP), and $1 \mathrm{mM}$ phenylmethanesulfonyl fluoride (PMSF)] and lyzed using sonication. The lysate was then cleared by centrifugation $\left(12,000 \mathrm{~g}\right.$ for $1 \mathrm{~h}$ at $\left.4^{\circ} \mathrm{C}\right)$ and was applied to Glutathione Sepharose $4 \mathrm{~B}$ resin for further purification. After washing with the binding buffer ( $50 \mathrm{mM}$ Tris, $\mathrm{pH} 7.3,300 \mathrm{mM} \mathrm{NaCl}$ ), the target protein was eluted with elution buffer (50 mM Tris, $\mathrm{pH} 7.3$, $300 \mathrm{mM} \mathrm{NaCl}, 10 \mathrm{mM}$ reduced glutathione). All fractions were collected and monitored by SDS-polyacrylamide gel electrophoresis. After the addition of $1 \mathrm{mM}$ dithiothreitol (DTT), the protein was used for further enzymatic assay.

\section{BRD4 Assay}

Compounds were evaluated in biochemical bromodomain binding assays. The acetylated histone $\mathrm{H} 4$ (H4K5acK8acK12acK16ac) was synthesized as a substrate, $\mathrm{Eu}^{3+}$ cryptate and $\mathrm{d} 2$ beads (Cisbio, France) were used as energy donor and energy acceptor, respectively. BRD4 (BD1) or BRD4 (BD2), acetylated histone $\mathrm{H} 4$, candidate compound and buffer are present in the $20 \mu \mathrm{l}$ system. After incubated $30 \mathrm{~min}$ in $25^{\circ} \mathrm{C}$, fluorescence signal was detected by microplate reader (Envision, PerkinElmer, United States) with excitation at $320 \mathrm{~nm}$, emission at 665 and $615 \mathrm{~nm}$. The final TR-FRET signal was signal $665 \mathrm{~nm} /$ signal $615 \mathrm{~nm} \times 10,000 \mathrm{~nm}$. Test compounds that compete with the biotinylated ligand for BRD4 binding can reduce the TR-FRET signal. \% inhibition = [(compound signal $)$ - (min signal $)] /[($ max signal $)-($ min signal $)]$ $\times$ 100. $\mathrm{IC}_{50}$ was analyzed by GraphPad 9.0 (La Jolla, CA, United States).

\section{Dialysis Experiment}

The BRD4 (BD1) or BRD4 (BD2) recombinant was incubated with 100 folds of the $\mathrm{IC}_{50}$ of candidate compound at $37^{\circ} \mathrm{C}$ for $30 \mathrm{~min}$, then the mixture was dialyzed against the assay buffer with five times changing for each $2 \mathrm{~h}$. Finally, the mixture before 
and after dialysis was subjected to test the activity of BRD4 with above mentioned TR-FRET assay. JQ-1 was used as a positive control.

\section{Dilution Assay}

The BRD4 (BD1) or BRD4 (BD2) recombinant was incubated with 100 folds of the $\mathrm{IC}_{50}$ of candidate compound at $37^{\circ} \mathrm{C}$ for $30 \mathrm{~min}$, then the mixture was diluted 100 folds to test the activity of BRD4 with above mentioned TR-FRET assay. JQ-1 was used as a positive control.

\section{Protein Thermal Shift Assay}

BRD4(BD1) or BRD4(BD2), SYPRO Orange (Thermo Fisher, United States), candidate compound and PBS buffer are present in the $20 \mu \mathrm{l}$ system. Then real-time PCR instrument (QuantStudio 7, Applied Biosystems, United States) was used to heat from 25 to $95^{\circ} \mathrm{C}$ and detect fluorescence signal. d (Fluorescence)/dT and $\Delta \mathrm{Tm}$ was analyzed.

\section{Cellular Thermal Shift Assay (CETSA)}

CETSA (Martinez Molina and Nordlund, 2016) was performed to confirm the cellular interaction between BRD4 and SN-38 in vitro. The K562 cells were collected and suspended in the PBS. Then, cell suspension was freeze-thawed repeatedly for three times using liquid nitrogen, and the supernatant was collected by centrifuge at $20,000 \mathrm{~g}$ for $20 \mathrm{~min}$ at $4^{\circ} \mathrm{C}$. After that, the protein was incubated with SN-38 for $30 \mathrm{~min}$, and divided into six tubes in average. The tube was then heated at indicated temperature for $3 \mathrm{~min}$, and cooled for $3 \mathrm{~min}$. The supernatant was then transferred to a new microtubule after centrifuge at $20,000 \mathrm{~g}$ for $20 \mathrm{~min}$ at $4^{\circ} \mathrm{C}$, and analyzed by sodium dodecyl sulfate polyacrylamide gel electrophoresis (SDS-PAGE) followed by western blot analysis.

\section{Western Blotting Analysis}

Using radio immunoprecipitation assay (RIPA) buffer to lysate cells, the protein concentration was then determined by bicinchoninic acid (BCA) method. After that, the collected protein was denatured in the presence of loading buffer (Takara, Japan) and subjected to SDSPAGE with same amount. After running, the isolated protein on gel was transferred to the $0.2 \mu \mathrm{m}$ nitrocellulose (NC) membrane (Pall, United States). Following the blockage with 5\% milk, the membrane was incubated with primary antibody and secondary antibody, respectively. Finally, the membrane was imaged with X-ray film (Kodak, Japan) with the help of electrochemiluminescence (ECL) imaging kit (ThermoFisher, United States). The antibodies used in this study are as follows: Ki67 antibody (HuaBio, ET1609-34, China), BRD4 Antibody (AFFINITY, DF2905, United States), C-MYC antibody (HuaBio, 0912-2, China), active + pro caspase-3 antibody (HuaBio, ET1608-64, China), GAPDH antibody (Goodhere, AB-P-R001, China), Bcl-XL antibody (HuaBio, ET1603-28, China), BAX antibody (Proteintech, 50599-2-Ig, United States), peroxidase affiniPure goat anti-rabbit IgG $(\mathrm{H}+\mathrm{L})$ (Jackson Immumo Research, 111-035-003, United States).

\section{Apoptotic Analysis}

The apoptosis was quantified by fluorescence activated cell sorting (FACS) with Annexin V-FITC/PI staining kit from
BioVision (United States). Ten-thousand events for each sample were counted and analyzed by Accuri C6 flow cytometer (BD, United States). The early and late apoptotic cells were identified by the localization of Annexin V and PI.

\section{Molecular Docking}

Crystal structure of the first bromodomain of BRD4 (PDB: 6CD4) was obtained from the RCSB Protein Data Bank (Wang et al., 2018). Molecular docking was performed by Molecular Operating Environment (MOE) modeling software 2014.0901. The process includes the preparation of the protein and ligand and docking. The preparation of BRD4 was performed as follows, deletion of water molecules, adding hydrogen atoms, assigning the partial charges and energy minimization. The ligand binding pocket residues of BRD4 were identified by Site Finder from MOE. And chemical structures of SN-38 were input as mol2 format, and the conformation was optimized using energy minimization and conformational search. Finally, SN-38 was docked into BRD4 using Dock from MOE. And favorable ligand conformation is selected and analyzed using Discovery Studio Visualizer 4.5.

\section{Statistical Analysis}

Data was analyzed by GraphPad Prism Version 9.0. $t$-test or oneway analysis of variance (ANOVA) was used for statistical significance evaluation and ${ }^{* *} p<0.01$ was considered statistically significant.

\section{RESULTS AND DISCUSSION}

\section{SN-38 was Identified as a Novel Potent BRD4 Inhibitor Using Drug Repurposing Strategy}

To identify BRD4 inhibitor with novel skeleton, a Food and Drug Administration (FDA)-approved drug library containing 2,864 compounds from SelleckChem was applied to BRD4 screening assay using Time-Resolved Fluorescence Resonance Energy Transfer (TR-FRET) method (Figure 1A). In the first round, all candidate compounds were subjected to BRD4 (BD1) assay at $10 \mu \mathrm{M}$. Then, compounds that can inhibit BRD4 (BD1) activity with more than $50 \%$ were collected and subjected to the secondround screening at $1 \mu \mathrm{M}$. After that, compounds that can inhibit BRD4 (BD1) activity with more than $50 \%$ at $1 \mu \mathrm{M}$ were subjected to the $\mathrm{IC}_{50}$ evaluation, and $\mathrm{SN}-38$ (Figure 1B) was characterized as one of the most potent BRD4 (BD1) inhibitor with $\mathrm{IC}_{50}=$ $660.2 \mathrm{nM}$ with hillslope $=0.9724$ (Figure 1C), while JQ-1 can inhibit BRD4 (BD1) with $\mathrm{IC}_{50}=163.2 \mathrm{nM}$. In addition, SN-38 can also inhibit BRD4 (BD2) with $\mathrm{IC}_{50}=506.1 \mathrm{nM}$ with hillslope $=0.9562$ (Figure 1C), while JQ-1 can inhibit BRD4(BD1) with $\mathrm{IC}_{50}=123.9 \mathrm{nM}$. To further evaluate the binding property of SN-38 to BRD4, the protein thermal shift assay (Huynh and Partch, 2015) was used to detect the $\Delta \mathrm{Tm}$ between the Tm (BRD4 + $6 \mu \mathrm{M}$ SN-38) value and the blank Tm (BRD4 + DMSO), using JQ-1 as the control compound. As indicated in Table 1, for BRD4 (BD1) and BRD4 (BD2), the $\triangle \mathrm{Tm}$ increased upon SN-38 and JQ-1 treatment. The results 


\section{A}

B<smiles>CCc1c2c(nc3ccc(O)cc13)-c1cc3c(c(=O)n1CC)COC(=O)[C@]3(O)CC2</smiles>

C
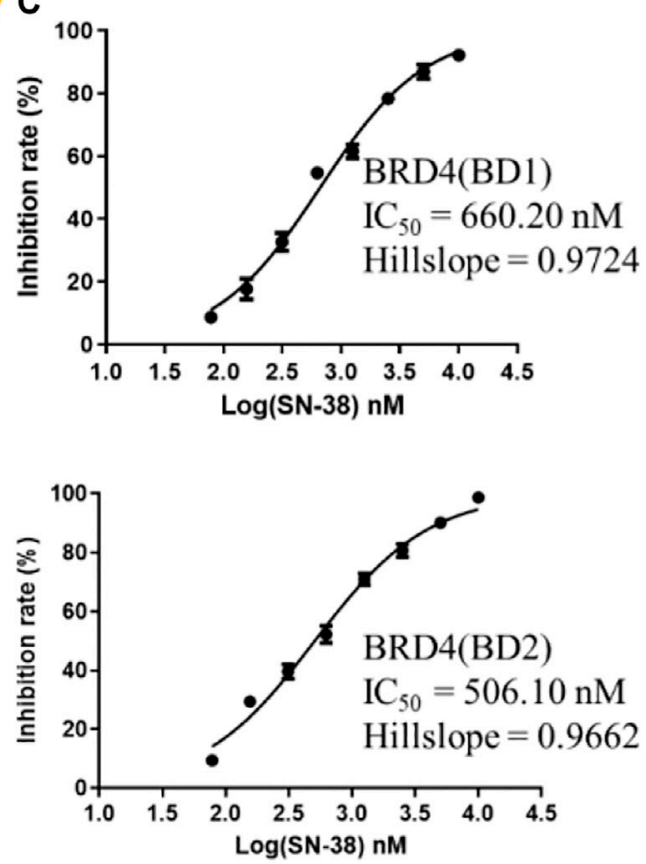

D

E

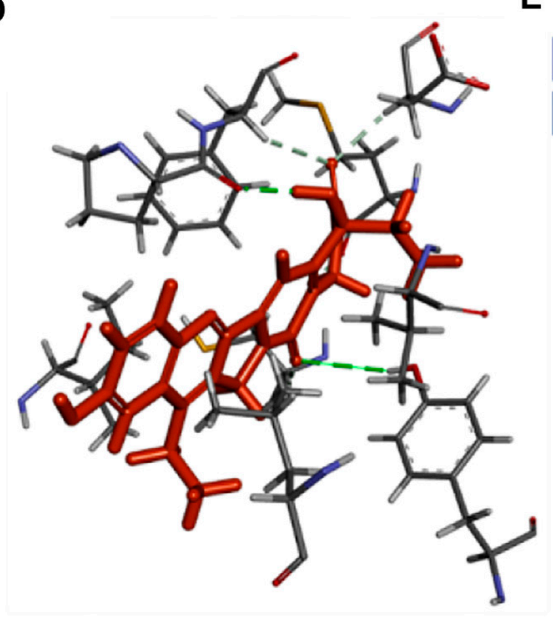

Conventional hydrogen bond

Carbon hydrogen bond

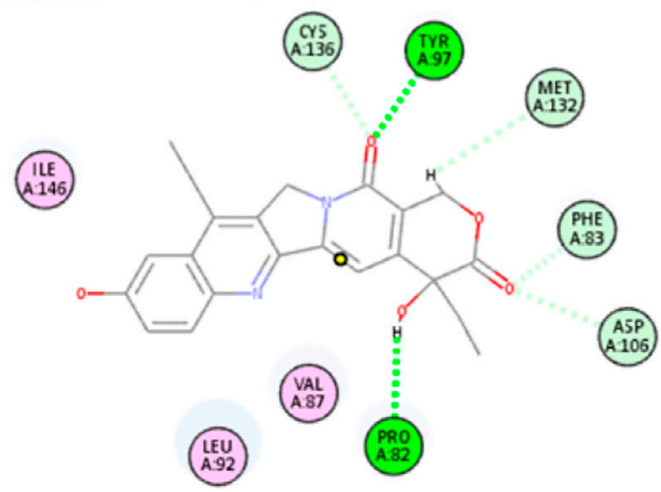

FIGURE 1 | Identification of SN-38 as a potent BRD4 inhibitor. (A) Flowchart about the identification of SN-38 as a BRD4 inhibitor. (B) Structure of SN-38; (C) Inhibition curve of SN-38 against BRD4(BD1) (up) and BRD4 (BD2) (down) recombinant. (D) Molecular modeling of SN-38 in the first bromodomain of BRD4 (PDB: 6CD4); (E) he Hydrogen bond interaction between BRD4 and SN-38 (PDB: 6CD4). Data were shown as mean \pm SD with three times replication.

TABLE 1 | Protein thermal shift assay performed with SN-38 and JQ-1.

\begin{tabular}{lcc}
\hline & Compound & $\boldsymbol{\Delta} \mathbf{T m}\left({ }^{\circ} \mathbf{C}\right)$ \\
\hline BRD4(BD1) & JQ-1 & 9.4 \\
& SN-38 & 5.8 \\
BRD4(BD2) & JQ-1 & 11.6 \\
& SN-38 & 6.3
\end{tabular}

suggest that JQ-1 and SN-38 can enhance the stability of BRD4 (BD1) and BRD4 (BD2) recombinant. Molecular modeling also suggested that SN-38 can interact with first bromodomain of
BRD4 (Figure 1D) and form classical hydrogen bond with TYR97 and PRO82 (Figure 1E), respectively, indicating the importance of carbonyl and hydroxy group of SN-38. Meanwhile, several carbon hydrogen bonds were also formed (Figure 1E). All these findings confirmed that SN-38 can bind and inhibit BRD4 potently.

\section{SN-38 Inhibited BRD4 in a Reversible Manner and Inhibit K562 Proliferation}

As we have confirmed that SN-38 can inhibit BRD4 potently, whether this process is reversible or not remains unknown. So, to 


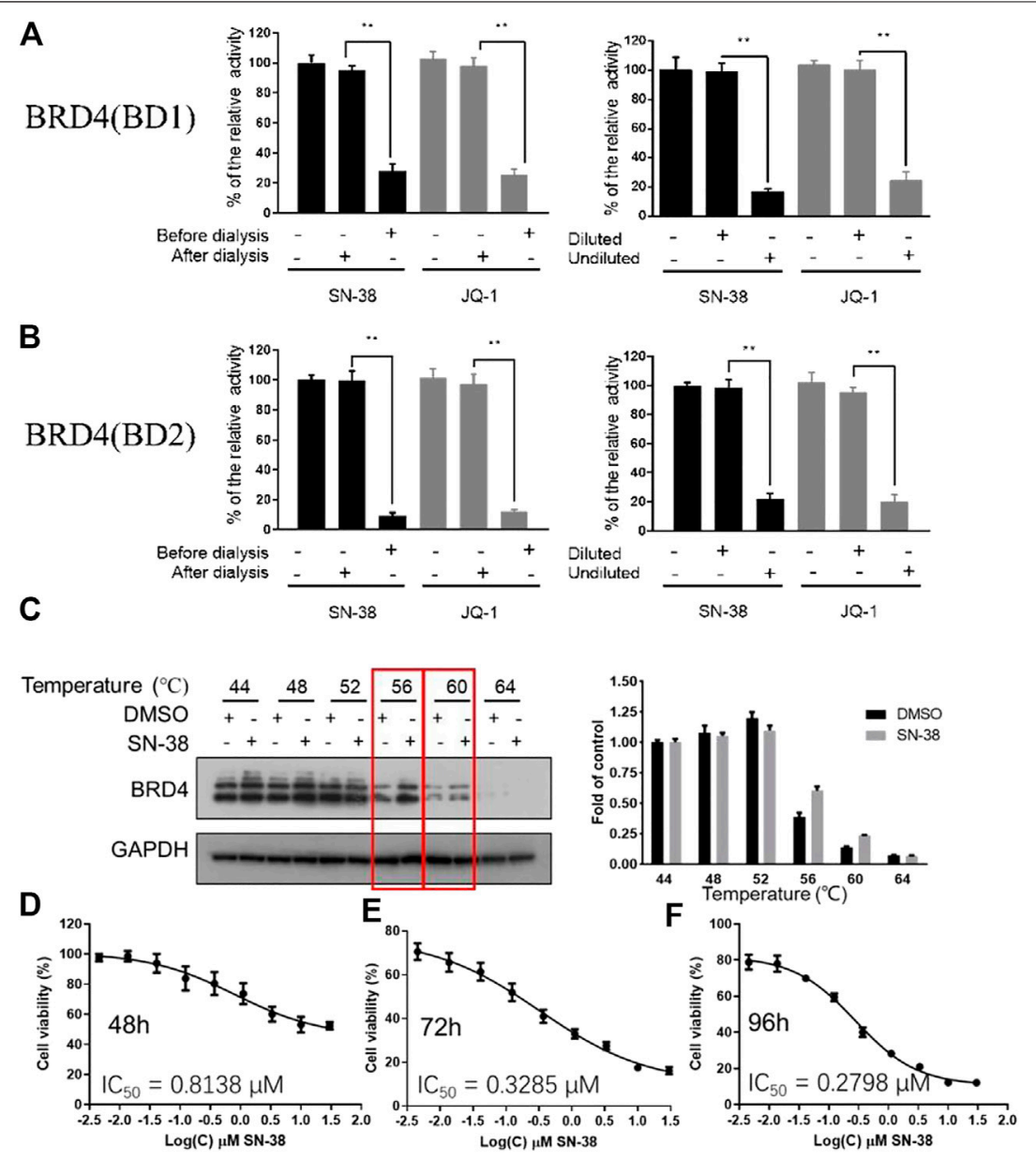

FIGURE 2|SN-38 inhibited BRD4 (BD1) and BRD4 (BD1) in a reversible manner, SN-38 can bind BRD4 and inhibit cell proliferation in K562 cells. (A,B) Reversible test of SN-38 against BRD4 (BD1) (up) and BRD4 (BD2) (down) recombinant using dialysis assay and dilution assay. JQ-1 was used as a positive control. (C) Protein levels of BRD4 in K562 cells treated with SN-38 using CETSA. (D-F) Cell viability of K562 cells that exposed to SN-38 fir $48 \mathrm{~h}$ (D), $72 \mathrm{~h}$ (E) or $96 \mathrm{~h}$ (F), respectively. ${ }^{\star \star} p<$ 0.01 were considered statistically significant compared diluted group vs. undiluted group. Data were shown as mean \pm SD with three times replication.

test the reversibility of SN-38 against the binding between BRD4 and its histone substrate, dialysis experiment and dilution assay were applied. After the co-incubation of BRD4 (BD1) recombinant and $33 \mu \mathrm{M}$ SN-38, the mixture was subjected to BRD4 (BD1) assay, and result in Figures 2A,B suggested that $33 \mu \mathrm{M}$ SN-38 can inhibit BRD4 (BD1) completely, while depletion of $\mathrm{SN}-38$ by dialysis can recover the activity of BRD4 (BD1), indicating that $\mathrm{SN}-38$ may be a reversible inhibitor against BRD4 (BD1). To further support this result, dilution assay was also applied. While the recombinant BRD4 (BD1) was incubated with SN-38 at the concentration of $33 \mu \mathrm{M}$ for $30 \mathrm{~min}$, then the mixture was diluted 100-fold and subjected to the BRD4 (BD1) assay. As shown in Figures 2A,B, after the dilution, the enzymatic activity was significantly restored, which further suggested that $\mathrm{SN}-38$ is a reversible BRD4 (BD1) inhibitor. Additional dialysis experiment and dilution assay using BRD4 (BD2) assay also gave solid evidence that SN-38 is not only a reversible BRD4 (BD1) inhibitor, but also inhibited BRD4 (BD2) reversibly.
As we have confirmed that SN-38 can bind and inhibit BRD4 potently in a reversible manner, whether $\mathrm{SN}-38$ can interact with BRD4 in cellular level is still unknown. So, to answer this question, CETSA was performed in $\mathrm{K} 562$ cells in the presence of SN-38 at different temperature. As indicated in Figure 2C, when the protein in $\mathrm{K} 562$ was denatured at 56 and $60^{\circ} \mathrm{C}$ in the presence of $\mathrm{SN}-38, \mathrm{BRD} 4$ protein can be stabilized, indicating the cellular target engagement of SN-38 in K562 cells. Further cell viability suggested that $\mathrm{SN}-38$ can inhibit K562 cell proliferation with $\mathrm{IC}_{50}=0.8138 \mu \mathrm{M}$ for $48 \mathrm{~h}$ treatment (Figure 2D), $\mathrm{IC}_{50}=$ $0.3285 \mu \mathrm{M}$ for $72 \mathrm{~h}$ treatment (Figure $2 \mathrm{E}$ ), $\mathrm{IC}_{50}=0.2798 \mu \mathrm{M}$ for $96 \mathrm{~h}$ treatment (Figure 2F). All data above indicated that SN-38 can bind BRD4 and inhibit K562 proliferation.

\section{SN-38 can Induce the Apoptosis of K562 Cells}

To explore cytotoxicity of SN-38 in K562 cells, apoptotic analysis was also performed with Annexin V-FITC/PI double staining and 
A

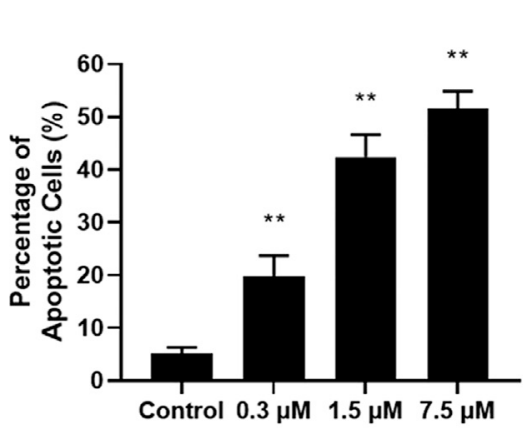

B
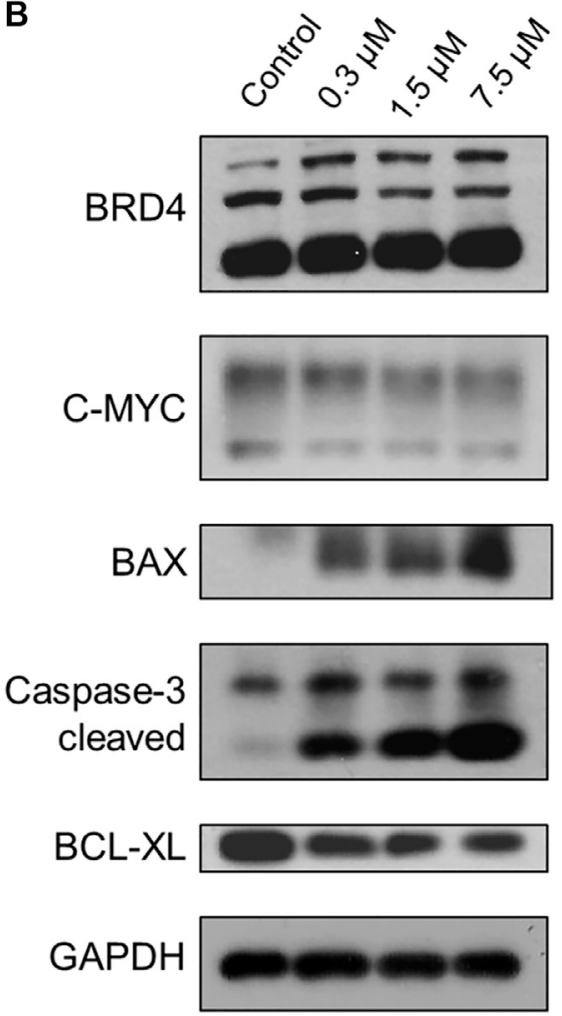

C
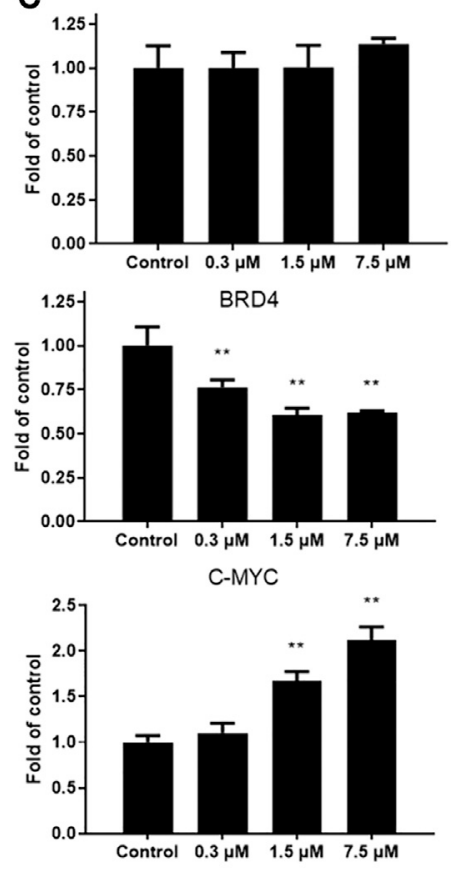

$\mathrm{BAX}$
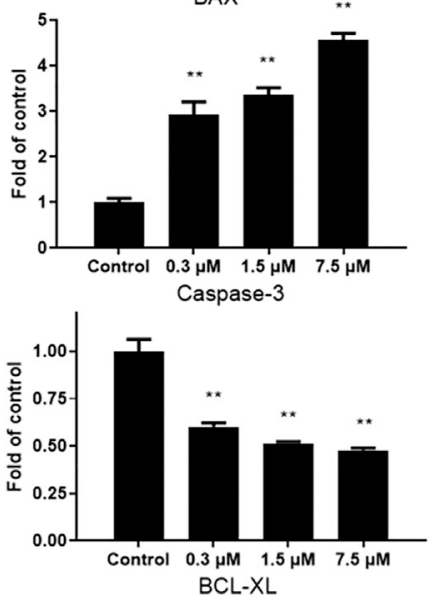

FIGURE 3 |SN-38 regulated the expression of apoptotic related protein and induced apoptosis of K562 cells. (A) The apoptotic percentage of K562 cells treated with different doses of SN-38; (B), (C) Expression levels of apoptosis-related proteins in K562 cells treated with different doses of SN-38 for 48 h. Data were shown as mean \pm SD with three times replication. ${ }^{\star \star} p<0.01$ were considered statistically significant compared to control group.

quantitated by flow cytometry. SN-38 treatment of K562 cells dose dependently increased the percentage of the apoptotic population up to $19.68,42.43$, and $51.65 \%$, respectively, compared to control (5.56\%) (Figure 3A). To further explore the mechanism, expression of BRD4 was investigated when cells were exposed to SN-38 for $48 \mathrm{~h}$. As shown in Figures 3B, C, SN-38 does not change the expression of BRD4. Nevertheless, substrate of BRD4 (Delmore et al., 2011), C-MYC, was decreased in a dose dependent manner. On the other hand, protein levels of cleaved caspase- 3 and BAX were upregulated upon SN-38 treatment, while the apoptosis inhibitor BCL-XL was decreased. Therefore, it was confirmed that SN-38 can inhibit BRD4 and decrease the expression of its substrate C-MYC in cells, meanwhile $\mathrm{SN}-38$ can regulate apoptotic related protein expression and induce cell apoptosis.

\section{CONCLUSION}

In summary, with a small compound library screening, $\mathrm{SN}-38$ was characterized to bind and inhibit $\mathrm{BRD} 4$ with $\mathrm{IC}_{50}=660.2 \mathrm{nM}$ against BRD4 (BD1), and $\mathrm{IC}_{50}=547.7 \mathrm{nM}$ against BRD4 (BD2) using drug repurposing strategy. Additional dialysis experiment and dilution assay gave a support that SN-38 can inhibit BRD4 (BD1) and BRD4 (BD2) in a reversible manner. Further cellular 
studies showed that $\mathrm{SN}-38$ can stabilize BRD4 in cells, indicating that $\mathrm{SN}-38$ can bind BRD4 in cellular level. Meanwhile, we found that $\mathrm{SN}-38$ can significantly suppress the proliferation of human leukemic cell $\mathrm{K} 562$ with $\mathrm{IC}_{50}=0.8138 \mu \mathrm{M}$ for $48 \mathrm{~h}$ treatment, $\mathrm{IC}_{50}=0.3285 \mu \mathrm{M}$ for $72 \mathrm{~h}$ treatment, $\mathrm{IC}_{50}=0.2798 \mu \mathrm{M}$ for $96 \mathrm{~h}$ treatment, respectively, while the clinical applied BRD4 inhibitor OTX015 inhibited K562 proliferation with IC50 $=11.342 \mu \mathrm{M}$ for $72 \mathrm{~h}$ treatment (Coudé et al., 2015), indicating the superiority of SN-38 as a dual targets inhibitor. Based on the molecular docking study, SN-38 was found to interact with first bromodomain of BRD4 and form strong hydrogen bond with TYR97 and PRO82, respectively, indicating the importance of carbonyl and hydroxy group of SN-38, this information may support the medicinal chemists to further optimize $\mathrm{SN}-38$ as a dual target inhibitor. In addition to these findings, SN-38 was confirmed to induce the apoptosis in a dose dependent manner and inhibit the expression of BRD4 substrate C-MYC, and induce the cleavage of caspase-3 and expression of BAX. Meanwhile, it can downregulate the expression of BCL-XL. All of our findings gave an evidence that SN-38 may serve as a new potent and reversible BRD4 inhibitor in biochemical level and cellular level, and may be used for the treatment of human leukemic cell.

\section{REFERENCES}

Alqahtani, A., Choucair, K., Ashraf, M., Hammouda, D. M., Alloghbi, A., Khan, T., et al. (2019). Bromodomain and extra-terminal motif inhibitors: a review of preclinical and clinical advances in cancer therapy. Future Sci. OA 5 (3), FSO372. doi:10.4155/fsoa-2018-0115

Andrieu, G., Belkina, A. C., and Denis, G. V. (2016). Clinical trials for BET inhibitors run ahead of the science. Drug Discov. Today Tech. 19, 45-50. doi:10. 1016/j.ddtec.2016.06.004

Coudé, M. M., Braun, T., Berrou, J., Dupont, M., Bertrand, S., Masse, A., et al. (2015). BET inhibitor OTX015 targets BRD2 and BRD4 and decreases c-MYC in acute leukemia cells. Oncotarget 6 (19), 17698-176712. doi:10.18632/oncotarget.4131

Delmore, J. E., Issa, G. C., Lemieux, M. E., Rahl, P. B., Shi, J., Jacobs, H. M., et al. (2011). BET bromodomain inhibition as a therapeutic strategy to target c-Myc. Cell 146 (6), 904-917. doi:10.1016/j.cell.2011.08.017

Feinberg, A. P., and Tycko, B. (2004). The history of cancer epigenetics. Nat. Rev. Cancer 4 (2), 143-153. doi:10.1038/nrc1279

Filippakopoulos, P., and Knapp, S. (2014). Targeting bromodomains: epigenetic readers of lysine acetylation. Nat. Rev. Drug Discov. 13 (5), 337-356. doi:10.1038/nrd4286

Filippakopoulos, P., Picaud, S., Mangos, M., Keates, T., Lambert, J. P., Barsyte-Lovejoy, D., et al. (2012). Histone recognition and large-scale structural analysis of the human bromodomain family. Cell (1) 149, 214-231. doi:10.1016/j.cell.2012.02.013

Fujinaga, K., Luo, Z., Schaufele, F., and Peterlin, B. M. (2015). Visualization of positive transcription elongation factor $\mathrm{b}(\mathrm{P}-\mathrm{TEFb})$ activation in living cells. J. Biol. Chem. 290 (3), 1829-1836. doi:10.1074/jbc.m114.605816

Huynh, K., and Partch, C. L. (2015). Analysis of protein stability and ligand interactions by thermal shift assay. Curr. Protoc. Protein Sci. 79, 28.29.21-28.29.14. doi:10.1002/0471140864.ps2809s79

Itzen, F., Greifenberg, A. K., Bösken, C. A., and Geyer, M. (2014). Brd4 activates P-TEFb for RNA polymerase II CTD phosphorylation. Nucleic Acids Res. 42 (12), 7577-7590. doi:10.1093/nar/gku449

Kulikowski, E., Rakai, B. D., and Wong, N. C. W. (2021). Inhibitors of bromodomain and extra-terminal proteins for treating multiple human diseases. Med. Res. Rev. 41 (1), 223-245. doi:10.1002/med.21730

Marmorstein, R., and Roth, S. Y. (2001). Histone acetyltransferases: function, structure, and catalysis. Curr. Opin. Genet. Develop. 11 (2), 155-161. doi:10. 1016/s0959-437x(00)00173-8

Martinez Molina, D., and Nordlund, P. (2016). The cellular thermal shift assay: a novel biophysical assay for in situ drug target engagement and mechanistic

\section{DATA AVAILABILITY STATEMENT}

The original contributions presented in the study are included in the article/Supplementary Material, further inquiries can be directed to the corresponding author.

\section{AUTHOR CONTRIBUTIONS}

CW and SW designed and directed the experiments. AW performed the experiments and wrote the manuscript. LL collected and analyzed the experimental data. ML investigated the relevant literature and revised the manuscript. All authors read and approved the final manuscript.

\section{FUNDING}

This work was supported by grants from National Natural Science Foundation of China (Nos. U1804191 and 81800137) and The Youth Scholars Foundation for the Basic research and Cultivation of Zhengzhou University.

biomarker studies. Annu. Rev. Pharmacol. Toxicol. 56, 141-161. doi:10.1146/ annurev-pharmtox-010715-103715

Morinière, J., Rousseaux, S., Steuerwald, U., Soler-López, M., Curtet, S., Vitte, A. L. et al. (2009). Cooperative binding of two acetylation marks on a histone tail by a single bromodomain. Nature 461 (7264), 664-668. doi:10.1038/nature08397

Roe, J. S., Mercan, F., Rivera, K., Pappin, D. J., and Vakoc, C. R. (2015). BET bromodomain inhibition suppresses the function of hematopoietic transcription factors in acute myeloid leukemia. Mol. Cel 58 (6), 1028-1039. doi:10.1016/j.molcel.2015.04.011

Sahai, V., Redig, A. J., Collier, K. A., Eckerdt, F. D., and Munshi, H. G. (2016). Targeting BET bromodomain proteins in solid tumors. Oncotarget 7 (33), 53997-54009. doi:10.18632/oncotarget.9804

Schaefer, U. (2014). Pharmacological inhibition of bromodomain-containing proteins in inflammation. Cold Spring Harb Perspect. Biol. 6 (6), a018671. doi:10.1101/cshperspect.a018671

Taniguchi, Y. (2016). The bromodomain and extra-terminal domain (BET) family: functional anatomy of BET paralogous proteins. Int. J. Mol. Sci. 17 (11), 1849. doi:10.3390/ijms17111849

Theodoulou, N. H., Tomkinson, N. C., Prinjha, R. K., and Humphreys, P. G. (2016). Clinical progress and pharmacology of small molecule bromodomain inhibitors. Curr. Opin. Chem. Biol. 33, 58-66. doi:10.1016/j.cbpa.2016.05.028

Wang, J., Erazo, T., Ferguson, F. M., Buckley, D. L., Gomez, N., Muñoz-Guardiola, P., et al. (2018). Structural and atropisomeric factors governing the selectivity of pyrimido-benzodiazipinones as inhibitors of kinases and bromodomains. ACS Chem. Biol. 13 (9), 2438-2448. doi:10.1021/acschembio.7b00638

Wu, S. Y., and Chiang, C. M. (2007). The double bromodomain-containing chromatin adaptor Brd4 and transcriptional regulation. J. Biol. Chem. 282 (18), 13141-13145. doi:10.1074/jbc.r700001200

Conflict of Interest: The authors declare that the research was conducted in the absence of any commercial or financial relationships that could be construed as a potential conflict of interest.

Copyright (c) 2021 Wang, Li, Li, Wang and Wang. This is an open-access article distributed under the terms of the Creative Commons Attribution License (CC BY). The use, distribution or reproduction in other forums is permitted, provided the original author(s) and the copyright owner(s) are credited and that the original publication in this journal is cited, in accordance with accepted academic practice. No use, distribution or reproduction is permitted which does not comply with these terms. 